\title{
Remediation and its biological responses of Cd contaminated sediments using biochar and minerals with nanoscale zero-valent iron loading
}

\author{
Qunqun Liu ${ }^{\mathrm{a}, \mathrm{b}}$, Yanqing Sheng ${ }^{\mathrm{a}, *}$, Wenjing Wang ${ }^{\mathrm{a}}$, Changyu $\mathrm{Li}^{\mathrm{a}}{ }^{\mathrm{a} b}$, Guoqiang Zhao ${ }^{\mathrm{a}, \mathrm{b}}$ \\ ${ }^{a}$ Research Center for Coastal Environment Engineering Technology of Shandong Province, Yantai Institute of Coastal Zone Research, Chinese Academy of Sciences, Yantai, China \\ ${ }^{\mathrm{b}}$ University of Chinese Academy of Sciences, Beijing, China
}

\section{H I G H L I G H T S}

- The nZVI loaded biochar and mineral enhanced immobilization of $\mathrm{Cd}$ in sediments.

- Bacterial composition, richness and diversity were changed after immobilization.

- DOM presented autogenetic characteristics with bacterial community changes.

- $\mathrm{BC}(\mathrm{nZVI} / \mathrm{BC})$ possessed higher immobilization performance than minerals.

\section{A R T I C L E I N F O}

\section{Article history}

Received 16 November 2019

Received in revised form 27 December 2019

Accepted 10 January 2020

Available online 15 January 2020

Editor: Daniel CW Tsang

\section{Keywords:}

Sediment immobilization

Cadmium (Cd)

Nanoscale zero-valent ion

Dissolved organic carbon

Enzyme activity

Bacterial community
G R A P H I C A L A B S T R A C T

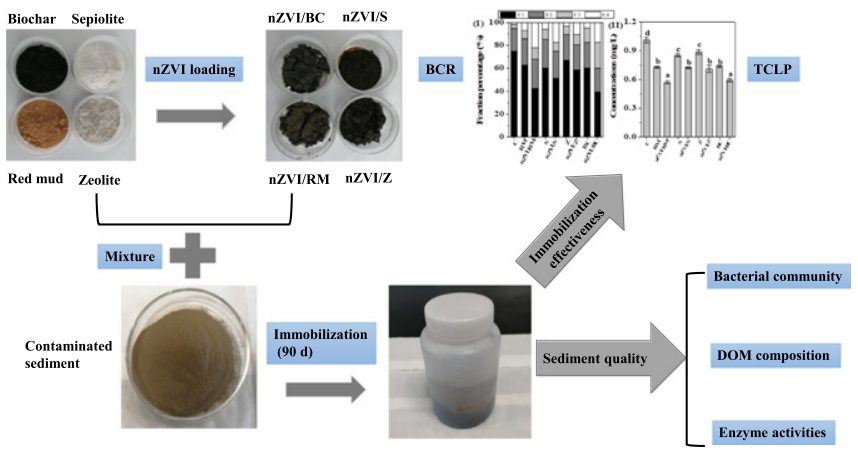

\section{A B S T R A C T}

Remediation of $\mathrm{Cd}$ pollution in sediments is crucial for the safety of aquatic environments and human health. In this study, four effective, common, and low-cost remediation materials (zeolite, sepiolite, red mud (RM), and biochar $(\mathrm{BC})$ ) loaded with nanoscale zero-valent iron (nZVI) and themselves were employed to immobilize Cd in sediments. The effects of different materials on sediment properties, immobilization effectiveness, bacterial communities, enzyme activities, and dissolved organic matter (DOM) were investigated. Results showed that sediment properties were significantly changed by the addition of immobilization materials $(P<0.05)$. The geochemical fraction analysis showed that the labile $\mathrm{Cd}$ was partially transformed to the stable fraction after immobilization, with an $11-47 \%$ decrease in the acid-soluble fraction and a $50-1000 \%$ increase in the residual fraction. The Cd immobilization effectiveness peaked at the $\mathrm{nZVI} / \mathrm{RM}$ and $\mathrm{nZVI} / \mathrm{BC}$ treatments, and the Cd toxicity characteristic leaching procedure (TCLP) leachabilities decreased by $42 \%$ and $44 \%$, respectively. The modified materials were more effective for immobilizing $\mathrm{Cd}$ than the raw materials owing to the presence of $\mathrm{nZVI}$, and the $\mathrm{Cd}$ TCLP leachabilities with the modified materials decreased by $15 \%-22 \%$ compared with the raw material treatments. Immobilization-driven reduction of bioavailable $\mathrm{Cd}$ enhanced the richness and diversity of bacterial communities and enzyme activities. Moreover, the immobilization treatment promoted the $\mathrm{Fe}(\mathrm{III})$-reducing process by increasing the Fe(III)-reducing bacteria (e.g. Geobacteraceae, Bacillus, and Clostridium), which are conducive to Cd immobilization. Additionally, the DOM composition presented more autogenetic characteristics in treated groups. BC (nZVI/BC) can be selected as the priority material for $\mathrm{Cd}$ immobilization in sediments due to higher immobilization effectiveness and lower adverse effects on sediments.

(C) 2020 Elsevier B.V. All rights reserved.

\footnotetext{
* Corresponding author.

E-mail address: yqsheng@yic.ac.cn (Y. Sheng).
} 


\section{Introduction}

Heavy metal pollution has been regarded as a global environmental problem because of high toxicity, persistence, non-biodegradability, and bioaccumulation (Q. Liu et al., 2018). Cadmium (Cd) is a widespread and typical heavy metal in sediments. It has a higher toxicity and mobility than many other heavy metals (such as $\mathrm{Cu}, \mathrm{Zn}$, and $\mathrm{Pb}$ ) (Huang et al., 2018a). Moreover, Cd can accumulate in the human body through the food chain to cause bone and kidney damage and even increase cancer risks (Li et al., 2019). Sediments play an important role in the transport and storage of toxic heavy metals in aquatic ecosystems; the accumulated heavy metals in surface sediments can be released to overlying water when environmental factor changes (Q. Liu et al., 2018). Thus, remediation of Cd-contaminated sediments is imperative.

Conventional remediation of heavy metal-contaminated sediments, such as landfilling and disposal, can result in cost burdens, waste of land resources, and groundwater pollution (Wang et al., 2015). Electrochemical remediation and washing are limited by the cost and scale of application (Beiyuan et al., 2017). Notably, in-situ immobilization has been considered an economic, simple, and eco-friendly technique (Wang et al., 2019). The choice of remediation materials is very important for in-situ immobilization of heavy metals in sediments. Among many remediation materials, nanoscale zero-valent iron (nZVI) can effectively remove heavy metal pollution because of high reactivity, including reduction, complexation, and (co-)precipitation; moreover, nZVI has been proven to be a relatively eco-friendly agent (Yang et al., 2018). Therefore, nZVI is a promising material for remediation of heavy metals in sediment. However, nZVI tends to aggregate rapidly due to its magnetic property and small size, which greatly inhibits its reactivity (Xue et al., 2018b). To resolve this problem, synthesized nZVI particles have been usually supported on different surface-modified materials to enhance its removal ability on heavy metals (Cai et al., 2019). Zeolite, sepiolite, RM, and biochar (BC) are low-cost mineral and carbon-based materials that have been used to remove heavy metal pollution with high efficiencies (Mahar et al., 2015). Additionally, the large specific surface areas of these materials can also be conducive to the dispersion of nZVI. Therefore, they are very well suited as surface-modified materials of nZVI. The nZVI-loaded materials have been commonly employed for the removal of heavy metals from water/wastewater. For example, Sun et al. (2019) and Yang et al. (2018) reported that BC-supported nZVI composites can be effective for removing heavy metals from wastewater. Nevertheless, nZVI-loaded materials are rarely used in heavy metal remediation in sediments.

The main purpose of heavy metal immobilization is to reduce the bioavailability and toxicity of heavy metals to organisms; bioavailability and toxicity are closely related to their fractions rather than total concentrations (Q. Liu et al., 2018). A valid immobilization remediation should decrease bioavailability of heavy metals while avoiding sediment quality deterioration. Enzymes can actively participate in organic matter decomposition and nutrient cycling in sediments and enzyme activity is closely related to environmental conditions (Xu et al., 2017). Enzyme activity is commonly used as evidence of the effects of immobilization on heavy metal toxicity and bioavailability (Huang et al., 2017). Microbial communities not only serve important functions in sediment ecosystems, but also regulate many sediment processes (e.g. nutrient cycling, energy flow, and organic matter turnover) (Liu et al., 2018; Oyetibo et al., 2019). The application of immobilization materials can have positive effects on microbial communities in sediments (Huang et al., 2016). However, some indigenous microbes may be limited because immobilization materials can change sediment properties of, or directly poison microorganisms in the environment (Huang et al., 2017; Liu et al., 2018). Therefore, the influence of immobilization materials on sediments should be assessed before application in sediment remediation to reduce adverse effects and screen out ecofriendly materials.
Although sediment dissolved organic matter (DOM) constitutes only a small portion of sediment organic matter, it is a reactive and labile portion that potentially reflects the sediment quality (H. Xu et al., 2019). DOM is a major carbon source for microbial communities in sediments because of its biologically derived materials (e.g. proteins, polysaccharides, and humic-substances) (Xu et al., 2013). DOM composition changes with the microbial community during the heavy metal immobilization process (Yang et al., 2019). Therefore, identification and quantification of DOM is needed to understand the effects and mechanisms of remediation in heavy metal polluted sediments. Moreover, due to its multi-functionality and negative potential, sediment DOM can trap heavy metal ions to form organometallic complexes, which can influence the fate and transport of heavy metals (Wang et al., 2017). However, immobilization-induced changes to sediment DOM are still unclear.

The aims of this study were to (1) investigate immobilization effects of different materials on Cd polluted sediments before and after loading with nZVI, (2) identify the changes and mechanisms of bacterial communities, enzyme activities, and DOM in sediments after immobilization, (3) synthetize or select effective materials for $\mathrm{Cd}$ polluted sediment remediation. These results will be useful for further clarification of the underlying mechanisms of benefits associated with the immobilization and/or risks to pollution prevention and sediment quality.

\section{Materials and methods}

\subsection{Sediment sampling and characteristics}

Surface sediment samples $(0-10 \mathrm{~cm})$ were collected from the Guangdang River (Yantai City, China). Guangdang River is an urban river that primarily receives domestic sewage and industrial effluent, which cause serious heavy metal pollution in sediments. Collected sediment samples were air-dried and sieved through $2 \mathrm{~mm}$ mesh to obtain a homogenous sample. The determination methods for physiochemical properties and heavy metal concentrations in sediments are listed in Supporting Information Text S1 and the results are shown in Table 1.

\subsection{Material preparation}

BC, zeolite, sepiolite, and red mud (RM) were loaded with nZVI to explore their immobilization effects on $\mathrm{Cd}$ in sediments. The materials loaded with nZVI were synthesized by the liquid-phase method of Luo et al. (2019) and procedures are detailed in Supporting Information Text S2. The synthetic materials nZVI/red mud, nZVI/zeolite, nZVI/sepiolite, and nZVI/biochar are abbreviated as nZVI/RM, nZVI/Z, nZVI/S and $\mathrm{nZVI} / \mathrm{BC}$, respectively.

\subsection{Characterization of immobilization materials}

The cation exchange capacity (CEC) of BC, zeolite, sepiolite, and RM was determined by the ammonium acetate method (SSC, 2000). The pH

Table 1

The primary characteristics of raw sediments.

\begin{tabular}{ll}
\hline & Mean \pm standard deviation $(\mathrm{n}=3)$ \\
\hline $\mathrm{pH}$ & $7.98 \pm 0.04$ \\
$\mathrm{EC}\left(\mathrm{mS} \mathrm{cm}^{-1}\right)$ & $0.44 \pm 0.06$ \\
Particle size $(\%)$ & Clay: $2.95 ;$ Silt: $32.50 ;$ Sand: 64.55 \\
Total organic carbon (TOC, \%) & 3.73 \\
Total P (TP) $\left(\mathrm{g} \mathrm{kg}^{-1}\right)$ & $2.04 \pm 0.23$ \\
Total N (TN) $\left(\mathrm{g} \mathrm{kg}^{-1}\right)$ & $3.44 \pm 0.19$ \\
Water content $(\%)$ & $51.61 \pm 0.80$ \\
$\mathrm{Cd}\left(\mathrm{mg} \mathrm{kg}^{-1}\right)$ & $40.03 \pm 0.67$ \\
$\mathrm{Cu}\left(\mathrm{mg} \mathrm{kg}^{-1}\right)$ & $251.39 \pm 11.57$ \\
$\mathrm{~Pb}\left(\mathrm{mg} \mathrm{kg}^{-1}\right)$ & $161.40 \pm 5.55$ \\
$\mathrm{Zn}\left(\mathrm{mg} \mathrm{kg}^{-1}\right)$ & $386.93 \pm 24.68$ \\
\hline
\end{tabular}


and electrical conductivity (EC) in the raw materials were measured in the same way as in the sediment samples. The Brunauer-Emmett-Teller (BET) specific surface areas of immobilization materials were characterized using an automatic surface analyzer (Quantachrome, USA). The morphologies of different materials were scanned using scanning electron microscopy (SEM) (S-4800, Hitachi, Japan). The crystal structures of materials were measured by X-ray diffraction (XRD) (Empyrean, PANalytical B.V. Netherlands). Fourier-transform infrared spectroscopy (FTIR, Nicolet iS50, Thermo Fisher, USA) was used to identify the surface functional groups of immobilization materials.

\subsection{Experimental setup}

Effects of different materials on Cd immobilization, bacterial communities, enzyme activities, and DOM composition in sediments were investigated through incubation experiments. Based on the cost of remediation, level of $\mathrm{Cd}$ pollution in sediment, properties of remediation materials, and previous studies (Wang et al., 2019; Yang et al., 2019), the mass ratio of dry contaminated sediments and immobilization materials was set as 5\%. Briefly, $200 \mathrm{~g}$ air-dried sediment and $10 \mathrm{~g}$ immobilization material were mixed thoroughly in $500 \mathrm{~mL}$ high-density polyethylene bottles. All mixtures were gently covered with $250 \mathrm{~mL}$ deionized water. Then, all sediment samples were treated for $90 \mathrm{~d}$ at room temperature without light source. Three replicates were conducted for each group. The control groups were subjected to identical conditions without immobilization materials.

\subsection{Sediment chemical analyses}

After incubation, the overlying water in each bottle was carefully removed. The $\mathrm{pH}$, total organic carbon (TOC) and EC in cultured sediments were determined. A supernatant of 1:15 (w/v) suspension extracted with ultra-pure water was employed to determine the dissolved organic carbon (DOC). The DOC concentration in supernatant was measured using a TOC analyzer (TOC-VCPH, Shimadzu, Japan). The geochemical fractionation distribution can reflect the mobility and bioavailability of heavy metals (Q. Liu et al., 2018). In this study, the geochemical fractionations of $\mathrm{Cd}$ in sediments were measured using modified Bureau Communautaire de Référence (BCR) sequential extraction method (Q. Liu et al., 2018) and detailed produce is listed in Table S1. Toxicity characteristic leaching procedure (TCLP) was conducted to quantify the Cd leachability; this can also indicate Cd mobility and bioavailability (Huang et al., 2017; Liu et al., 2018). The TCLP extractant was $0.1 \mathrm{M}$ glacial acetic acid (solid-liquid ratio of 20 ) because the $\mathrm{pH}$ in all sediment samples was $>5$. The supernatants were filtered through a $0.45 \mu \mathrm{m}$ cellulose acetate membrane to test Cd by inductively coupled plasma mass spectrometer (ICP-MS, Optima 7000 DV, Perkin Elmer, USA) after shaking for $18 \mathrm{~h}$.

\subsection{Sediment DOM composition analysis}

For DOM determination, sediment samples were mixed with deionized water (solid-liquid ratio of 1:15) on a horizontal shaker for $24 \mathrm{~h}$, and supernatants were filtered through a $0.45 \mu \mathrm{m}$ cellulose acetate membrane to obtain the DOM (H. Xu et al., 2019). DOM composition was detected by three-dimensional excitation emission matrix (3DEEM) fluorescence spectroscopy (F-4500, Hitachi, Japan) at emission (Em) wavelength $250-550 \mathrm{~nm}$ and excitation (Ex) wavelength 200-450 nm. The increments of Em and Ex wavelengths were set as $2 \mathrm{~nm}$ and $5 \mathrm{~nm}$, respectively. Two fluorescent parameters-the fluorescence index (FIX, the ratio of fluorescence intensities between Em 450 and $500 \mathrm{~nm}$ at Ex $370 \mathrm{~nm}$ ) and the biological index (BIX, the ratio of fluorescence intensity at Em $380 \mathrm{~nm}$ to $430 \mathrm{~nm}$ at Ex $310 \mathrm{~nm}$ ) were calculated according to a previous report (H. Xu et al., 2019).

\subsection{Enzyme activity assays}

The urease activity in sediment was measured using the method of Hu et al. (2014), expressed as $\mathrm{NH}_{4}-\mathrm{N} \mathrm{mg} \mathrm{kg}^{-1}$. Catalase (CAT) activity was tested by titration with $0.1 \mathrm{M} \mathrm{KMnO}_{4}$, expressed as $\mathrm{mL} \mathrm{g}^{-1}$ (Sun et al., 2012). Dehydrogenase (DEH) activity was detected using a method described by Casida Jr. et al. (1964) and the reddish color intensity of the filtrate was determined using an ultraviolet-visible spectrophotometer (T6 New Century, Beijing Pgeneral, China) at a wavelength of $485 \mathrm{~nm}$.

\subsection{Bacterial community assays}

The total genome DNA extracted in samples was detected by the sodium dodecyl sulfonate/cetyltrimethylammonium bromide (SDS/ CTAB) method (Ha et al., 2015). Then, DNA was diluted to $1 \mu \mathrm{g} \mathrm{mL}-1$ using sterile water according to corresponding concentrations. The genomic DNA was amplified by PCR using the $16 \mathrm{~S}$ rRNA gene V4 region primers ( $515 \mathrm{~F}$ and $806 \mathrm{R}$ ). All PCR reactions were carried out in $30 \mu \mathrm{L}$ reactions with $15 \mu \mathrm{L}$ of Phusion ${ }^{\circledR}$ High-Fidelity PCR Master Mix, $0.2 \mu \mathrm{M}$ of forward and reverse primers, and $\sim 10 \mathrm{ng}$ template DNA. The PCR conditions were as follows: denaturation at $98^{\circ} \mathrm{C}$ for $1 \mathrm{~min}$, then 30 cycles $\left(98^{\circ} \mathrm{C}\right.$ for $10 \mathrm{~s}, 50{ }^{\circ} \mathrm{C}$ for $30 \mathrm{~s}, 72^{\circ} \mathrm{C}$ for $\left.30 \mathrm{~s}\right)$ and finally an extension at $72{ }^{\circ} \mathrm{C}$ for $5 \mathrm{~min}$. The amplified product was verified with $1.0 \%$ agarose gel electrophoresis. The PCR amplification product was further purified using a GeneJET ${ }^{\mathrm{TM}}$ Gel Extraction Kit (Thermo Scientific, USA). Sequencing libraries were generated using Ion Plus Fragment Library Kit 48 rxns (Thermo Scientific, USA). The library quality was evaluated based on the Qubit@2.0 Fluorometer (Thermo Scientific, USA). Finally, the library was sequenced with an Ion S5TM XL platform.

\subsection{Statistical analysis}

Analysis of variance (ANOVA) and Pearson correlation analysis were performed using SPSS 22.0. The canonical correspondence analysis (CCA), heatmap, and rarefaction curves were analyzed using $\mathrm{R}$ software. All significant levels were set as 0.05 . The parallel factor analysis (PARAFAC) model was applied to analyze sediment DOM composition. For bacterial community analysis, quality filtering on the raw reads was conducted carried out under specific filtering conditions to yield high-quality clean reads based on the Cutadapt quality control process. Uchime software was employed to remove the chimeras formed during the PCR to obtain the clean reads, and high-quality clean reads were clustered using Uparse software. Sequences with $\geq 97 \%$ similarity were classified as the same Operational Taxonomic Units (OTUs). The Silva Database was used to obtain the out representative sequence according to the Mothur algorithm to note taxonomic information. The ShannonWiener Index and abundance-based coverage estimator (ACE) were calculated using Qiime software.

\section{Results and discussion}

\subsection{Characterization of immobilization materials}

The RM, sepiolite, zeolite, and BC properties are presented in Table 2. All raw materials had $\mathrm{pH}>7$; such alkalinity is suitable for remediation of heavy metal contaminated sediments (Yin and Zhu, 2016). The EC in RM was higher than those of other materials, and zeolite exhibited the lowest EC. After nZVI loading, the specific surface area of the modified materials was larger than those of the corresponding raw materials. RM showed the highest CEC and zeolite showed the lowest CEC. Characteristic peaks of $\mathrm{Fe}^{\circ}$ at $2 \theta=44.9^{\circ}$ (ICDD 01-087-0721) were observed at nZVI/RM, nZVI/S, nZVI/Z, and nZVI/BC in XRD patterns (Fig. S1), but were not found in their raw materials. This indicates successful loading of nZVI nanoparticles. The SEM images of raw and modified materials were shown in Fig. S2. The surfaces of modified materials (Fig. S2(b), 
Table 2

Characteristics of immobilization materials.

\begin{tabular}{lllll}
\hline & RM & Sepiolite & Zeolite & BC \\
\hline $\mathrm{pH}$ & $10.30 \pm 0.11$ & $9.09 \pm 0.18$ & $8.99 \pm 0.08$ & $9.90 \pm 0.04$ \\
$\mathrm{EC}\left(\mathrm{mS} \mathrm{cm}^{-1}\right)$ & $2.87 \pm 0.11$ & $0.18 \pm 0.01$ & $0.16 \pm 0.02$ & $1.11 \pm 0.03$ \\
$\mathrm{BET}\left(\mathrm{m}^{2} \mathrm{~g}^{-1}\right)$ & $78.41 / 116.58$ & $40.63 / 74.29$ & $63.56 / 87.70$ & $51.05 / 103.40$ \\
$\mathrm{CEC}\left(\mathrm{cmol}^{+} \mathrm{kg}^{-1}\right)$ & 217.08 & 103.45 & 97.32 & 126.13
\end{tabular}

The values of before and after the oblique line are BET specific surface area of raw and modified materials, respectively.

(d), (f) and (h)) were found to be rougher than those of raw materials (Fig. S2(a), (c), (e) and (g)), causing increased specific surface areas in modified materials. Additionally, most globular nZVI particles existed independently rather than gathering together on the surfaces of raw materials. This indicates that raw materials can disperse nZVI to reduce the nanoparticle aggregation tendency. More importantly, the existence of core-shell structures in nZVI can provide reaction sites for the initial adsorption of metal ions, and the iron oxide shell can also stabilize metal ions through electrostatic interaction and surface complexation (Mu et al., 2017). Thus, nZVI loading can greatly strengthen adsorption abilities for heavy metals. The FTIR spectra were scanned in the range of $4000-400 \mathrm{~cm}^{-1}$, and the results are presented in Fig. S3. The absorption bands and peaks of different materials varied due to their different physiochemical properties. The minor differences of functional group distribution were observed between raw and modified materials, which indicating nZVI loading posed less influence on most of functional groups. Among many functional groups, the oxygen-containing functional groups played a very important role in heavy metal stabilization; for example, the $\mathrm{C}=\mathrm{O}$ and $-\mathrm{OH}$ functional groups showed very high coordination with the heavy metals (Yang et al., 2018). Therefore, the abundances of $\mathrm{C}=\mathrm{O}$ and $-\mathrm{OH}$ are conducive to heavy metal immobilization ability of these materials.

\subsection{Effects of immobilization material on sediment properties}

Sediment properties usually affect heavy metal behavior in sediments. The $\mathrm{pH}, \mathrm{EC}, \mathrm{TOC}$, and DOC changes in the sediments after immobilization are plotted in Fig. 1. In all treated groups, the $\mathrm{pH}$ significantly increased compared with control group $(P<0.05)$, and the maximum value appeared at nZVI/RM treatment (Fig. 1(I)). It was responsible for the gradual release of alkaline substances from immobilization materials (Yang et al., 2019). In sediments treated by modified materials, the $\mathrm{pH}$ was higher than in sediments with raw material treatments because $\mathrm{OH}^{-}$ions were released through nZVI oxidation according to the following reaction (Xue et al., 2018b):

$2 \mathrm{Fe}^{\mathrm{O}}+\mathrm{O}_{2}+2 \mathrm{H}_{2} \mathrm{O} \rightarrow 2 \mathrm{Fe}^{2+}+4 \mathrm{OH}^{-}$

Moreover, immobilization materials can stabilize heavy metals because higher $\mathrm{pH}$ favors metal precipitation and solubility reduction (Liu et al., 2018). Significant EC reinforcements were observed at all treatments (Fig. 1(II)), which is related to the release of $\mathrm{Na}, \mathrm{K}, \mathrm{Ca}$, and $\mathrm{Mg}$ (Yang et al., 2019). Overall, immobilization materials reduced TOC in treated sediments (Fig. 1(III)). However, TOC in BC and nZVI/BC treatments significantly increased compared with the control $(P<0.05)$ owing to the input of external organic carbon from BC. Due to microorganism decomposition, the part of organic carbon was transformed into DOC, causing DOC to increase in the treatment groups (Fig. 1(IV)).

\subsection{Changes in Cd mobility}

Heavy metals in sediments are divided into acid-soluble (F1), reducible (F2), oxidizable (F3), and residual (F4) fractions. Among them, F4 is universally considered the most stable fraction under natural conditions (Liu et al., 2018). However, heavy metals in non-residual fractions (the total of F1, F2, and F3) are easily mobilized when environmental factors changed, posing threats to ecosystem health again (Q. Liu et al., 2018). Changes of $\mathrm{Cd}$ fractions are illustrated in Fig. 2(I). It was found that $\mathrm{Cd}$ in raw sediments was dominated by F1 ( $75 \%$ of total, most bioavailable), but its fractions changed with the addition of immobilization materials after $90 \mathrm{~d}$ incubation. Overall, F1 decreased in treated sediment samples compared the control group. The proportions of F1 in treated samples shifted from initial $75 \%$ to $63 \%, 43 \%, 60 \%, 50 \%, 67 \%, 59 \%, 60 \%$ and $40 \%$ (with a decrease of 11-47\%) after the addition of RM, nZVI/RM, zeolite, $\mathrm{nZVI} / \mathrm{S}$, zeolite, nZVI/Z, BC, and nZVI/BC, respectively. Moreover, F4 increased from the initial $2 \%$ to $7 \%, 22 \%, 6 \%, 15 \%, 3 \%, 12 \%, 5 \%$, and $18 \%$
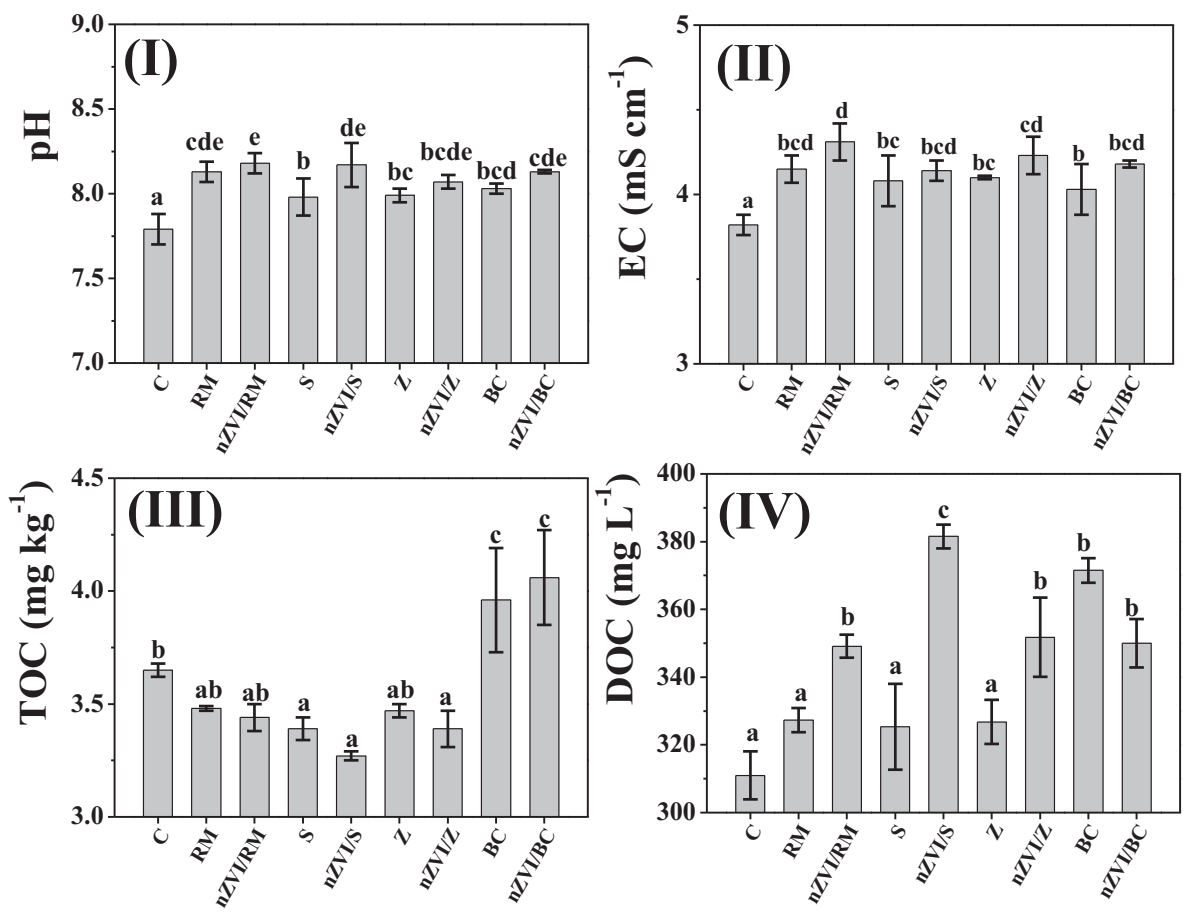

Fig. 1. The pH (I), EC (II), TOC (III), and DOC (IV) in sediments after immobilization (Different letters denote significant differences among groups $(P<0.05)$.) 

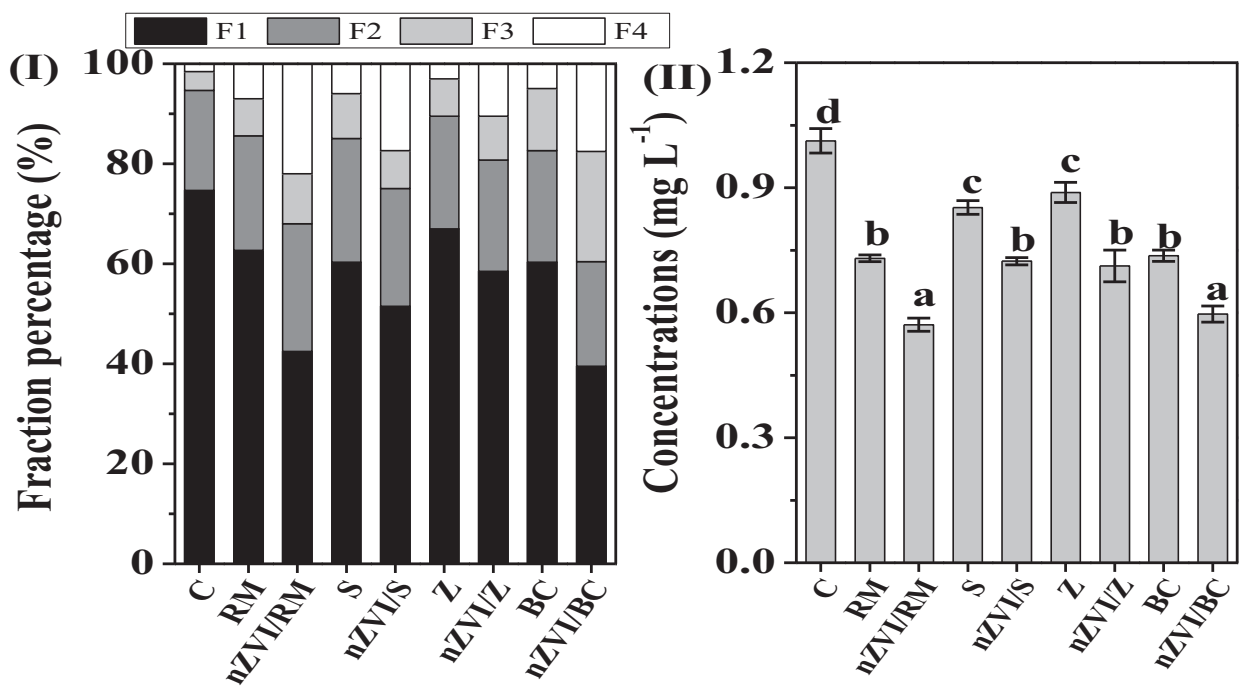

Fig. 2. Cd fractions (I), and TCLP-leachable values (II) in sediments after immobilization (Different letters denote significant differences among groups $(P<0.05)$.)

correspondingly (with an increase of 50-1000\%). Compared to the F1 and F4 fractions, changes in the proportions of the F2 and F3 fractions were relatively smaller, indicating that part of the F1 fraction was transformed into the F4 fraction after the immobilization materials were added. Decreased F1 and increased F4 fractions indicate great reduction in Cd mobility following immobilization. Notably, Cd in BC and RM treatments showed less F1 and more F4 fractions compared to zeolite and sepiolite, which had the lower mobilities. Previous studies have shown that oxygen-containing functional groups can stabilize metal ions through complexation (Luo et al., 2011; Cui et al., 2019); as discussed in Section 3.1, many $\mathrm{C}=\mathrm{O}$ and $-\mathrm{OH}$ of $\mathrm{BC}$ and $\mathrm{RM}$ in this study greatly enhanced the immobilization ability for $\mathrm{Cd}$. With the exception of complexation effects, $\mathrm{Cd}$ ions can also be trapped to form insoluble inorganic forms (e.g. metal-phosphate or metal-silicate) through association with the mineral and crystal lattices of BC and RM (Taneez and Hurel, 2019; Y. Xu et al., 2019). Moreover, compared to zeolite and sepiolite, higher pH makes BC (9.90) and RM (10.30) more conducive to $\mathrm{Cd}$ immobilization by enhancing the strong interactions with Cd ions (e.g. electrostatic attraction and surface-complexation), which could make more Cd remain F4 fraction (Xue et al., 2018a).

The differences of immobilization effects of raw and modified materials indicate that nZVI enhanced Cd immobilization efficiency. Specifically, the proportions of the F4 fraction at nZVI/RM, nZVI/S, nZVI/Z, and $\mathrm{nZVI} / \mathrm{BC}$ treatments increased by approximately $215 \%, 207 \%$, $283 \%$, and $254 \%$, respectively, compared to the raw materials. Meanwhile, the proportions of $\mathrm{F} 1$ fraction were decreased by $32 \%, 15 \%, 13 \%$, and $34 \%$, respectively. The Cd immobilization mechanisms induced by nZVI mainly included adsorption, surface complexation, and (co-)precipitation, rather than direct reduction. This is because the standard potential of $\mathrm{Cd}\left(\mathrm{E}^{\circ}=-0.40 \mathrm{~V}\right)$ is close to $\mathrm{Fe}\left(\mathrm{E}^{\circ}=-0.41 \mathrm{~V}\right)$ (Zhang et al., 2014). During nZVI preparation, iron oxidation can produce surface hydroxides in proximity to $\mathrm{FeOOH}$ (Baer et al., 2010). Similar to metal ion adsorption on Fe(III) oxide (e.g. goethite, ferrihydrite, and maghemite), this surface oxide layer supplies surface sites in coordination with $\mathrm{Cd}$ (Xue et al., 2018b). A previous study also confirmed that Cd was partly adsorbed or complexed by Fe(III) minerals (Huang et al., 2016). Additionally, the nZVI surface carries more negative charges in higher $\mathrm{pH}$ environment, thus exhibiting stronger electrostatic affinity toward the positively charged $\mathrm{Cd}^{2+}$ (Xue et al., 2018a).

The percentage of residual fractions after immobilization were sorted by order as follows: nZVI/RM $(22 \%)>\mathrm{nZVI} / \mathrm{BC}(18 \%)>\mathrm{nZVI} / \mathrm{S}$ $(15 \%)>n Z V I / Z(12 \%)$. The dispersion of nZVI on raw materials was closely related to its immobilization effect, and aggregation of nZVI would inhibit immobilization capacity (Huang et al., 2016). Due to different specific surface areas of raw materials (Table 2), the dispersion of nZVI was accordingly different on raw materials. The nZVI/RM and $\mathrm{nZVI} / \mathrm{BC}$ showed a higher specific surface area (116.58 and $103.40 \mathrm{~m}^{2}$ / $\mathrm{g}$, respectively) compared to other modified materials, and therefore was better able to immobilize Cd. Additionally, their raw materials with higher $\mathrm{pH}$ (10.30 and 9.90, respectively) were more effective in immobilizing $\mathrm{Cd}$.

The Cd immobilization effectiveness and bioavailability of sediments can also be assessed by TCLP (Wan et al., 2018); the results are shown in Fig. 2(II). TCLP-extractable Cd in all treated groups significantly decreased compared to the control $(P<0.05)$. The nZVI/BC and nZVI/RM exhibited the greatest decline in TCLP-extractable Cd (42\% and $44 \%$ decreases, respectively), suggesting lower bioavailability and higher immobilization effectiveness. The decline in TCLP-extractable $\mathrm{Cd}$ concentrations in zeolite and sepiolite treatment were relatively small. Additionally, the TCLP-extractable Cd in the modified material treatments was lower than in raw materials, indicating high immobilization effectiveness. Specifically, the TCLP-extractable Cd concentrations of $\mathrm{nZVI} / \mathrm{RM}, \mathrm{nZVI} / \mathrm{S}, \mathrm{nZVI} / \mathrm{Z}$, and nZVI/BC treatments decreased by approximately $22 \%, 15 \%, 20 \%$, and $19 \%$, respectively, compared to the raw material treatments. This phenomenon was consistent with $\mathrm{Cd}$ fraction analysis. Notably, unlike the fast adsorption of heavy metals by some materials loaded with nZVI in aqueous solutions (Inyang et al., 2016; Luo et al., 2019), the heavy metal immobilization process in sediment is slow.

\subsection{Bacterial community changes}

\subsubsection{Richness and diversity of bacterial communities}

A total of 721,140 valid reads and 6039 OTUs were received from 9 sediment samples using Illumina MiSeq analysis (Table S2). The rarefaction curves (near saturation) are shown in Fig. S4, suggesting that sequencing data were progressively reasonable. The relative abundances of bacterial 16S rRNA genes at the phylum and class levels were analyzed to study the composition of bacterial communities. The richness and diversity of bacterial community can be characterized using the abundance-based coverage estimator (ACE) (Chao and Lee, 1992) and Shannon-Wiener Index (Zhao et al., 2019), respectively. As shown in Table S2, all ACE and Shannon-Wiener Index values were higher than controls in treated sediments. This indicates that the richness and diversity of bacterial communities were enhanced by the addition of immobilization materials. Immobilization materials have high specific surface area and can therefore be used as carriers for enhancing microbe adhesion and growth (Qin et al., 2019). Specifically, the bacterial 
community richness peaked at $\mathrm{BC}(737.58)$ and nZVI/S (738.47) treatments, while richness diminished in nZVI/Z (661.67) and nZVI/RM (678.81) treatments. Similarly, higher bacterial community diversity was also observed at nZVI/S and BC treatments, while the lowest diversity was observed at RM treatment. Moreover, the richness of bacterial communities after nZVI/S treatment (738.47) was greater than after raw material treatment (682.40); however, the remaining groups showed the opposite trend. Similar phenomena also appeared regarding bacterial diversity. Interestingly, although RM (nZVI/RM) exhibited the greatest effectiveness for $\mathrm{Cd}$ immobilization among all raw (modified) materials, the richness and diversity of bacterial communities were lower than with BC (nZVI/BC) treatments. The reasons for this phenomenon was mainly because (1) the higher $\mathrm{pH}$ value of RM partly inhibited the bacterial growth compared to BC, and (2) BC changed bacterial communities by altering the carbon cycle and consequently affecting bacterial growth (Nielsen et al., 2011).

\subsubsection{Shifts in bacterial community and structure}

The relative abundances of bacterial 16S rRNA genes at the phylum and class levels are presented in Fig. 3. In the control, Firmicutes, Bacteroidetes and Proteobacteria were the dominant bacterial phyla, accounting for $22 \%, 21 \%$, and $38 \%$ of the total bacterial community, respectively (Fig. 3(a)). This finding agrees with the results of Guo et al. (2019) and Oyetibo et al. (2019), who determined that heavy metalcontaminated sediments were also dominated by Firmicutes, Bacteroidetes and Proteobacteria. Additionally, the relative abundance of the phyla Tenericutes, Planctomycetes, Armatimonadetes, Actinobacteria, Chloroflexi, and Latescibacteria comprised $6.84 \%$ of the total bacterial community.

After immobilization, the relative abundances of Firmicutes and Bacteroidetes increased by $33-90 \%$ and $9-88 \%$, respectively, in the treatments compared to the control. The Phyla Firmicutes was mostly comprised of various heavy metal-resistant genes, which can promote their adaptation to heavy metal polluted environments (Guo et al., 2019). Moreover, Firmicutes was classified as $r$-strategist, predominately occurring in suitable environmental conditions (Mackie et al., 2015). Thus, Firmicutes demonstrated enhanced relative abundance in treated sediments because of lower heavy metal toxicity. Similarly, Bacteroidetes was able to survive in heavy metal contaminated environments due to the ability to secrete sphingolipids, which protect cell
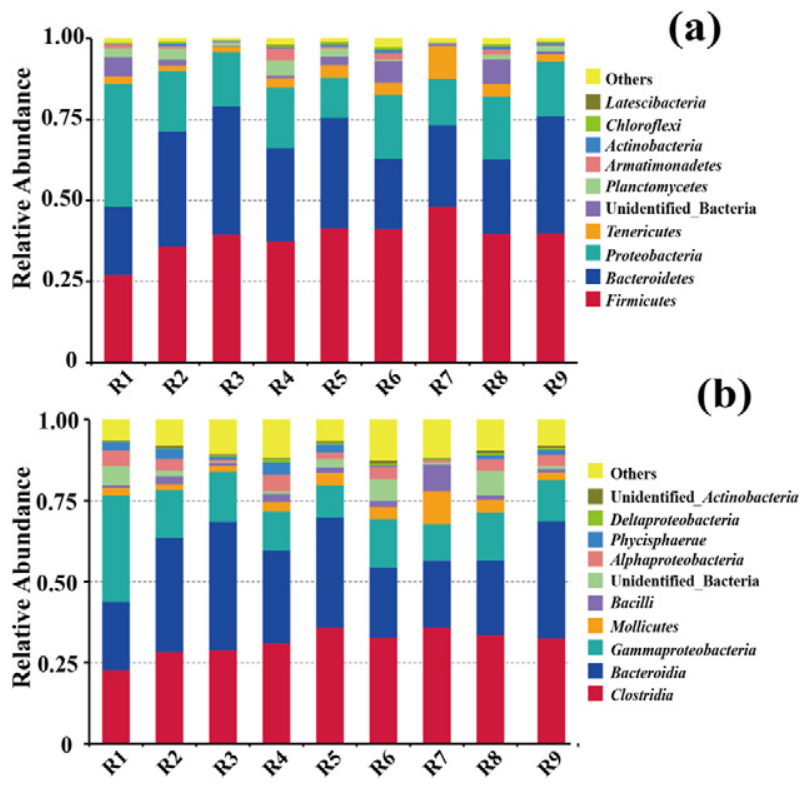

Fig. 3. The relative abundances of top 10 bacterial communities based on levels of phylum (a), and class (b, R1: control; R2: RM; R3: nZVI/RM; R4: sepiolite; R5: nZVI/S; R6: zeolite; R7: nZVI/Z; R8: BC; R9: nZVI/BC). surfaces and functions from various adverse stresses (Rickard et al., 2004). Additionally, many carriers provided by immobilization materials favored Firmicutes and Bacteroidetes growth. Particularly, the increases of relative abundance of Firmicutes in sediments treated by modified materials were higher than in raw materials ( $59 \%$ v.s. $43 \%$ on average). This phenomenon is a result of better immobilization effectiveness of materials loaded with nZVI on Cd in sediments. Interestingly, although Proteobacteria can also tolerate potentially toxic heavy metals (Kasemodel et al., 2019), its relative abundance decreased by $48-67 \%$. This decrease was probably caused by competition for mobile carbon between Proteobacteria and the fast-growing Firmicutes or Bacteroidetes (Huang et al., 2018b).

In Fig. 3(b), the relative abundance of Clostridia and Bacteroidia at the class level was increased by $24-109 \%$ and $3-88 \%$, respectively, compared to control, while a noticeable decrease (54-70\%) was observed at Gammaproteobacteria. Clostridia and Bacteroidia were wellconnected with organic matter degradation and organic acid production (Yang et al., 2016), and their enhancement indicated the quick consumption of organic matter in sediments. The hierarchical cluster analysis (Fig. 4) presents the genera responses to amendment after $90 \mathrm{~d}$ incubation. Alcaligenes, Proteiniphilum, Syntrophomonas, Pseudomonas, Caldicoprobacter, and Desulfosporosinus were dominant in the control (38\% of total). After immobilization, some of the original dominant genera weakened and new dominant genera (e.g. Halomonas, Gillisia, and Marinobacter in sepiolite treatment) appeared. Notably, the new dominant genera varied in different treated groups; this finding is consistent with Liu et al. (2018) and Xue et al. (2018b). It indicates that bacterial communities were sensitive to input of different materials at genus level. Particularly, the relative abundance of genera in the modified material treatment also showed great discrepancies compared to those in raw materials, suggesting that nZVI addition caused dramatic effects on bacterial communities at genus level.

\subsubsection{Relationship between Cd mobility and bacterial communities}

Cd mobility is highly impacted by Fe(III) reduction and the formation of new Fe mineral phases (Zhang et al., 2012). Firmicutes and Proteobacteria are the primary groups among Fe(III)-reducing bacterial (FeRB) communities. Geobacteraceae (affiliated to Proteobacteria) played an important role during the Fe(III) reduction process (Lovley, 1991). Relative abundance of Geobacteraceae in the control was almost negligible (accounting for only $0.01 \%$ ). However, its relative abundance greatly increased after immobilization (0.10-0.92\%), demonstrating that the $\mathrm{Fe}(\mathrm{III})$ reduction process was enhanced in the treated groups. Bacillus (affiliated to Firmicutes) participates in Fe(III) reduction (GilDíaz et al., 2017) and its relative abundance indicated a dramatic increase in the treated groups compared to the control (48-257\%). The relative abundance of Clostridium (affiliated to Firmicutes) was increased by $24-109 \%$, and it was confirmed to reduce Fe(III) through fermentation (Lin et al., 2007). Additionally, Actinobacteria, which increased by $23-358 \%$, was considered a rare FeRB phylum (Peng et al., 2016). Generally, Fe(III) reduction is often accompanied with reduction of sulfate by sulfate-reducing bacteria. Notably, sulfatereducing bacteria increased more in treated groups. Desulfovibrio (affiliated to Proteobacteria) and Desulfosporosinus (affiliated to Firmicutes) increased by $26-172 \%$ and $20-101 \%$, respectively. As reported by Muehe et al. (2013), hydrogen sulfide can be decomposed into HS $^{-}$, and then combine with $\mathrm{Cd}^{2+}$ to form $\mathrm{CdS}$. The Fe(III)-reducing bacteria can transform Fe and $\mathrm{Cd}$ transform into more stable Fe minerals, most likely magnetite, in reduction conditions while only a limited portion of them will transform into sulfides and carbonates (Xue et al., 2018b). Specifically, the relative abundance of these FeRB in sediments treated by modified materials had higher average rates of increase than raw materials (Bacillus: $393 \%$ vs. $95 \%$, Clostridium: $59 \%$ vs. $38 \%$, and Actinobacteria: $238 \%$ vs. $125 \%$ ). For Geobacteraceae, the average increase rates of modified material treatments were approximately 25 times higher than those of raw materials. Similar to FeRB, the average increase 


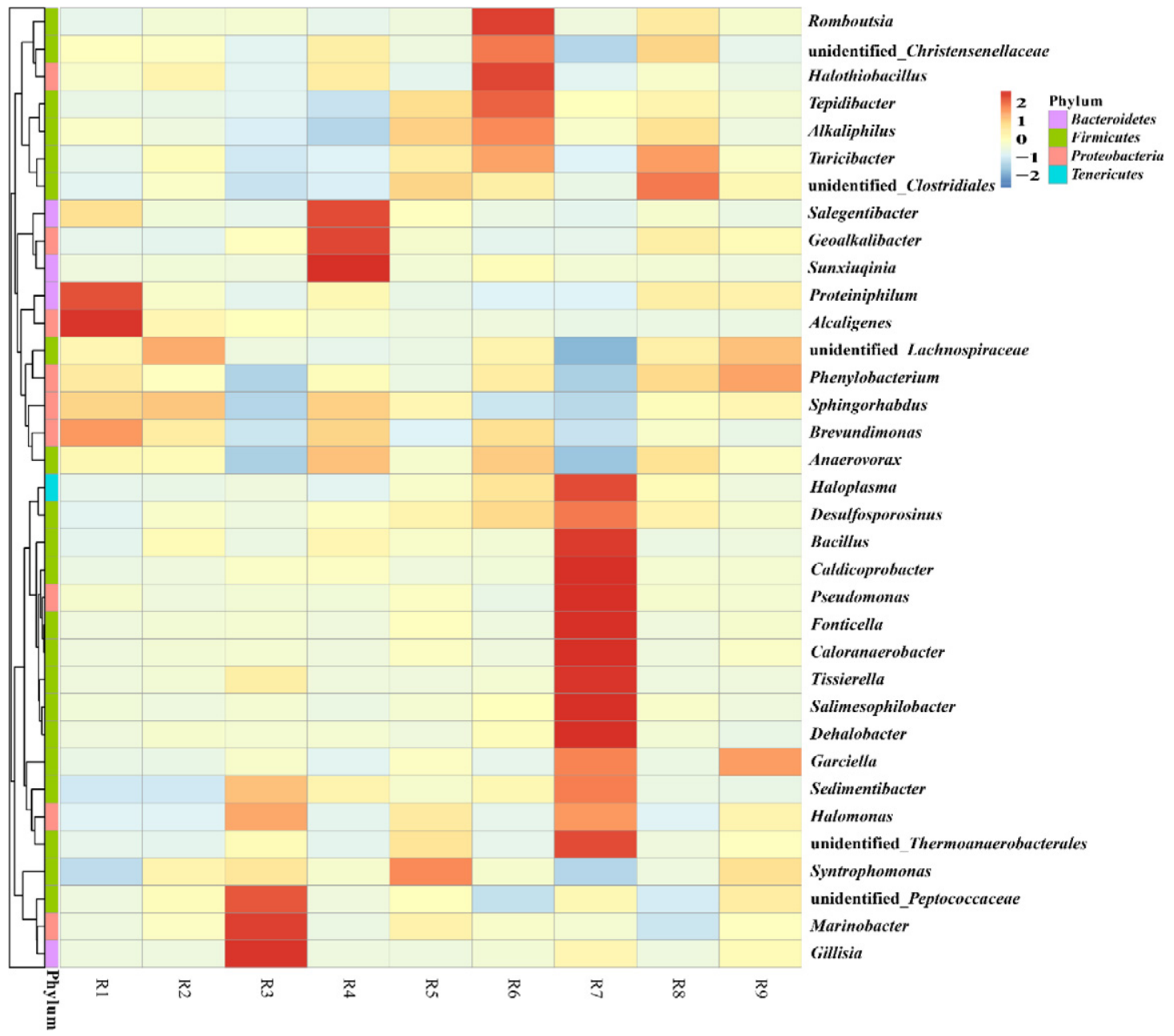

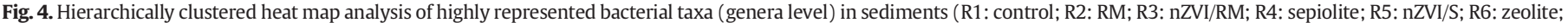
R7: nZVI/Z; R8: BC; R9: nZVI/BC).

rates of relative abundance in Desulfovibrio (77\% vs. 32\%) and Desulfosporosinus (90\% vs. 64\%) in modified material treatments were also higher than in raw materials. This illustrates that the addition of nZVI further promoted microbial $\mathrm{Fe}(\mathrm{III})$ and sulfate reduction that was also proved by Xue et al. (2018b). Overall, Cd immobilization in sediments was partly affected by bacterial activity through the intervening speciation transformation of Fe and $\mathrm{S}$.

\subsubsection{Environmental factors affecting bacterial communities}

The physicochemical properties and Cd bioavailability of sediments presented great changes after immobilization (Figs. 1 and 2). In this study, CCA was used to investigate the relationship among physicochemical properties, $\mathrm{Cd}$ bioavailability, and bacterial communities in sediments (Table 3 ). The bacterial community was significantly impacted by CEC, pH, TOC, DOC, and TCLP-extractable Cd $(P<0.05)$. The $\mathrm{pH}$ was able to affect heavy metal mobility and regulation of nutrients such as organic matter, which indirectly resulted in further changes to the bacterial community structure (Zhao et al., 2019). Moreover, pH chances can also directly influence bacterial growth and community composition (Wang et al., 2012). DOC was the most active type of organic carbon and the easiest for microorganism utilization ( $\mathrm{H} . \mathrm{Xu}$ et al., 2019). Therefore, DOC enhancement can promote bacterial growth. The decreased Cd bioavailability favored bacterial growth, allowing TCLP-extractable Cd to significantly influence the bacterial community. Overall, the addition of immobilization materials affects the bacterial community by changing its physicochemical properties and $\mathrm{Cd}$ bioavailability. This provides a supplementary explanation of why the diversity and richness of treated sediments were higher than the control (Section 3.4.1).

\subsection{Changes in DOM composition of sediments}

The chemical composition of sediment DOM was analyzed by the 3DEEM-PARAFAC model (Fig. S5). Four types of fluorescent components were identified, namely $\mathrm{C} 1, \mathrm{C} 2, \mathrm{C} 3$ and $\mathrm{C} 4$, respectively. C1 component loading peaked at $350 / 440 \mathrm{~nm}(\mathrm{Ex} / \mathrm{Em})$ and was classified as a fulviclike component (terrestrial origin) (Brym et al., 2014). C2 showed two peaks with $\mathrm{Ex} / \mathrm{Em}$ of $280 / 350$ and $280 / 420 \mathrm{~nm}$, respectively, and was assigned to protein- and tryptophan-like components that related to free molecules or bound amino acids from microbial degradation (Borisover et al., 2009). The maximum C3 and C4 values appeared at $310(260) / 390 \mathrm{~nm}(\mathrm{Ex} / \mathrm{Em})$ and $400(280) / 490 \mathrm{~nm}(\mathrm{Ex} / \mathrm{Em})$,

Table 3

Multivariate analysis of bacterial community structure in sediments using CCA.

\begin{tabular}{lrrll}
\hline Factors & \multicolumn{1}{l}{ RDA1 } & RDA2 & \multicolumn{1}{l}{$r^{2}$} & $\mathrm{P}$ \\
\hline $\mathrm{pH}$ & 0.619 & -0.785 & 0.949 & 0.000 \\
$\mathrm{EC}$ & 0.293 & -0.956 & 0.762 & 0.011 \\
TOC & -0.570 & -0.822 & 0.067 & 0.826 \\
DOC & 0.998 & 0.067 & 0.799 & 0.022 \\
TCLP-extractable Cd & -0.831 & 0.141 & 0.713 & 0.041 \\
\hline
\end{tabular}

RDA1 and RDA2 are the angle cosines of variable and the axes, respectively. $P$ : empirical $P$ values of fit statistic of environmental variables in RDA; $r^{2}$ : goodness of fit statistic. 

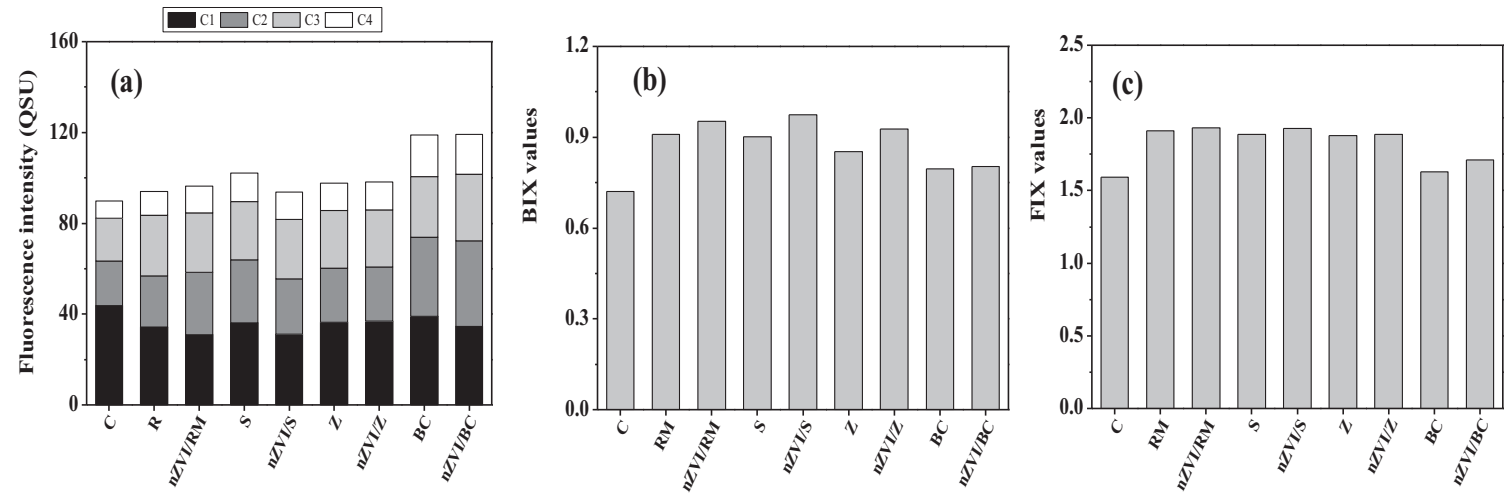

Fig. 5. The fluorescence intensity peaks (a) and 3D spectral characteristic parameters (b: BIX; c: FIX) of sediment DOM.

respectively, and all were assigned to microbial humic-like components (Yamashita et al., 2008).

Sediment DOM fluorescence intensity peaks can reflect concentrations of fluorescent components. All fluorescence intensity peaks of sediment DOM composition are shown in Fig. 5(a). The intensity peaks of treated groups were obviously higher than the control. BC and nZVI/ BC showed the highest intensity peak among all treated groups, suggesting that the addition of immobilization materials enhanced DOM production in sediments. Among them, BC or nZVI/BC showed the strongest enhancement effect compared to other material treatments owing to (1) the addition of $\mathrm{BC}$ or $\mathrm{nZVI} / \mathrm{BC}$ promoting greater bacterial growth, and thus more DOM production; (2) the input of external DOM sources from BC. Specifically, DOM can associate with metal ions through ion exchange, complexation, and chelation to reduce its migration, transformation, and biotoxicity; meanwhile, DOM can be adsorbed by immobilization materials, increasing their adsorption capacity (Wang et al., 2017). Therefore, DOM enhancement also favors Cd stabilization in sediments.

Regarding DOM composition, the C1 component concentrations in all treated sediments were lower than the control, whereas the other three components showed some increases. This indicates that DOM composition was changed by the addition of immobilization materials, which was also confirmed by FIX and BIX analysis. The DOMs in treated sediments were characterized by higher BIX (>0.8) (Fig. 5(b)) and DOMs in treated sediments were dominated by autochthonous contribution (Huguet et al., 2009). In the control, smaller BIX values indicate minor autochthonous contribution in DOMs compared with the treated groups. FIX was able to identify DOM sources with higher $(>1.4)$ and lower $(<1.2)$ values, indicating microbial and terrestrial sources, respectively (H. Xu et al., 2019). As shown in Fig. 5(c), the FIX values of all groups were $>1.4$, and the FIX of all treated groups were higher than the control, suggesting more DOM abundance of microbial sources in treated groups. These phenomena were attributed to the addition of immobilization materials, which promoted the production of microbially-derived organic matters, yielding autogenetic characteristics. Notably, the DOM composition intensity peaks, FIX, and BIX values of the raw material treatments showed minor differences compared to the modified material treatments. It suggests the presence of nZVI exerted limited impacts on changes of sediment DOM. This was because immobilization time was not long enough, and the influence of nZVI on DOM composition was still minor. Additionally, Pearson correlations showed that C2, C3 and C4 were highly correlated with the ACE and Shannon-Wiener Index (Table 4), suggesting that increased C2, C3 and C4 was the result of changes in bacterial activity. For instance, Bacteroidia and Clostridia were closely related to organic matter degradation and organic acid production. Their relative abundances were greatly enhanced in treated sediments, indicating release of microbially-derived organic matter and consumption of terrigenous organic matters.

\subsection{Changes in enzyme activities}

Catalase, urease, and dehydrogenase activities were used to investigate sediment quality after immobilization. Fig. 6 illustrates changes in catalase, urease, and dehydrogenase activities. In this study, only catalase activities were significantly higher in most treated groups than in the control $(P<0.05$, Fig. $6(\mathrm{I}))$. Catalase plays a key role in the $\mathrm{H}_{2} \mathrm{O}_{2}$ clear system in sediments; increased catalase activity indicated that the application of materials could effectively reduce $\mathrm{H}_{2} \mathrm{O}_{2}$ contents, maintain normal microorganism functions, and increase microorganism abilities to resist adverse environments (Sun et al., 2016). Although dehydrogenase and urease activities showed no significant increase in most treated groups, their activities were still higher than in the control. Generally, enzyme activities were not limited by addition of immobilization materials, because immobilization eased heavy metal toxicity.

Table 4

Pearson correlations among DOM composition, enzymes activity, and richness and diversity of bacterial community.

\begin{tabular}{|c|c|c|c|c|c|c|c|c|c|}
\hline & $\mathrm{C} 1$ & $\mathrm{C} 2$ & $\mathrm{C} 3$ & $\mathrm{C} 4$ & Urease & Catalase & $\mathrm{DEH}$ & ACE & Shannon-Wiener Index \\
\hline C1 & 1 & & & & & & & & \\
\hline $\mathrm{C} 2$ & -0.192 & 1 & & & & & & & \\
\hline $\mathrm{C} 3$ & $-0.714^{*}$ & $0.710^{*}$ & 1 & & & & & & \\
\hline C4 & -0.178 & $0.944^{* *}$ & $0.741^{*}$ & 1 & & & & & \\
\hline Urease & $-0.680^{*}$ & 0.161 & 0.363 & 0.103 & 1 & & & & \\
\hline Catalase & $-0.725^{*}$ & -0.083 & 0.502 & -0.065 & 0.274 & 1 & & & \\
\hline $\mathrm{DEH}$ & -0.080 & -0.281 & 0.062 & -0.059 & 0.024 & 0.247 & 1 & & \\
\hline ACE & -0.397 & 0.647 & $0.681^{*}$ & $0.671^{*}$ & 0.426 & 0.294 & 0.312 & 1 & \\
\hline Shannon-Wiener Index & -0.506 & 0.588 & 0.560 & 0.619 & 0.243 & 0.256 & 0.575 & $0.837^{* *}$ & 1 \\
\hline
\end{tabular}

\footnotetext{
* Correlation is significant at the 0.05 level.
}

** Correlation is significant at the 0.01 level. 

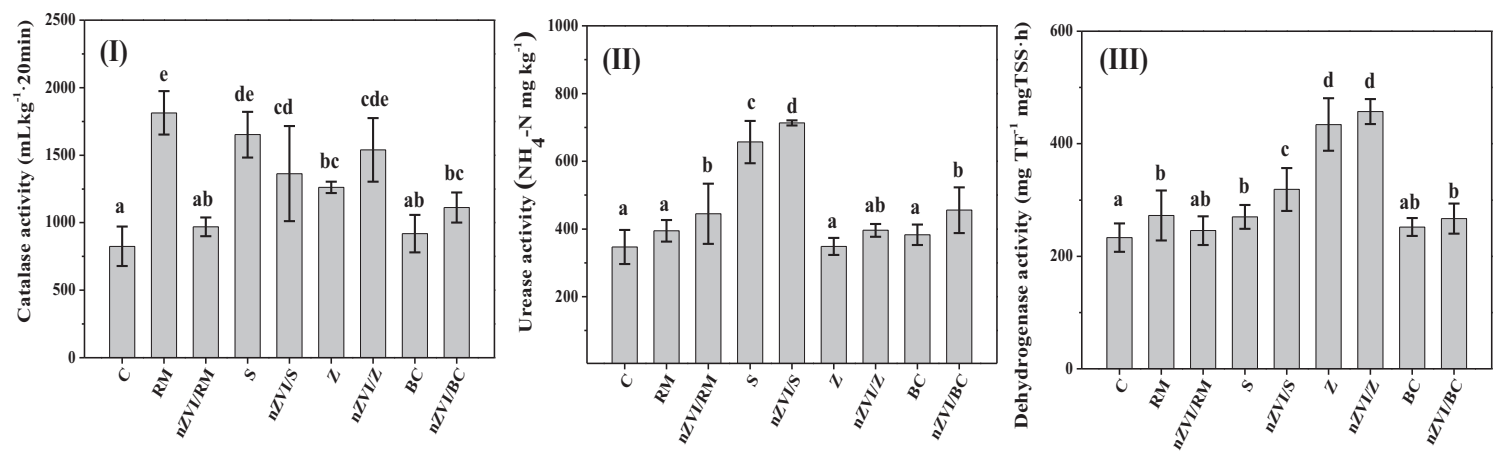

Fig. 6. Enzyme activities after immobilization: catalase (I), urease (II), and dehydrogenase (III) (Different letters denote significant differences among groups $(P<0.05)$.)

Notably, the increase rates in treated sediments were different from the control. Heavy metals can complex the sediment matrix, chelate sediment protein, react with the enzyme matrix and hinder microbial activity, thus affecting sediment enzyme activities (Moreno et al., 2003). However, changes in physiological properties induced by immobilization treatment can also affect enzyme activities. Particularly, varying degrees of $\mathrm{pH}$ changes occurred in different treated groups due the differences among immobilization materials (Fig. 2(I)), which also caused variation in enzyme activities. This variation caused urease and dehydrogenase activities to peak in sepiolite (nZVI/S) and zeolite ( $\mathrm{nZVI} / \mathrm{Z}$ ) groups whose $\mathrm{pH}$ values were closest to those of raw sediment ( 9.09 and 8.99 vs. 7.98). In contrast, although RM (nZVI/RM) exhibited the strongest immobilization effectiveness, enzyme activity enhancement was insignificant because its $\mathrm{pH}$ was higher than that of raw sediments (10.30 vs. 7.98). The enzyme activities showed no obvious regularity in raw and modified materials treatment groups. This phenomenon can be explained by differences in bacterial communities, $\mathrm{Cd}$ bioavailability, and sediment properties in the raw and modified materials treatment group. Specifically, there was no significant correlation among enzyme activities and bacterial richness and diversity (Table 4). This is likely because the strong adsorption capacity of enzymes or substrates caused them to be adsorbed by immobilization materials, disturbing enzyme activities (Bailey et al., 2011).

\section{Conclusions}

In this study, BC and minerals, alone and loaded with nZVI, were applied for the purpose of immobilizing $\mathrm{Cd}$ in sediments. The results of TCLP and BCR analysis showed that material additions favored Cd immobilization. The modified materials were more effective in $\mathrm{Cd}$ immobilization than the raw materials due to the presence of nZVI; BC (nZVI/BC) and RM (nZVI/RM) exhibited better Cd immobilization effectiveness. Following immobilization, bacterial richness and diversity and enzyme activities were enhanced due to the changes to sediment properties and Cd bioavailability. Particularly, applying immobilization materials facilitated $\mathrm{Fe}(\mathrm{III})$ reduction process by increasing the relative abundance of FeRB, which promoted Cd immobilization. Moreover, the DOM composition exhibited more autogenetic characteristics, which were related to changes in bacterial communities, in treated groups after immobilization. The nZVI greatly influenced bacterial community changes and enzyme activities while producing minor impacts on DOM composition. The addition of sepiolite and zeolite increased the diversity and richness of bacterial communities but had lower immobilization efficiencies than RM and BC. RM showed the highest immobilization effectiveness for Cd but improper RM application can damage raw sediment quality due to its higher $\mathrm{pH}$ value. Therefore, $\mathrm{BC}(\mathrm{nZVI} / \mathrm{BC})$ is recommended as the priority immobilization material in this study of Cd polluted-sediment remediation because of greater immobilization effectiveness and lower adverse effects on sediments. However, the $\mathrm{nZVI} / \mathrm{BC}$ is very expensive for practical application because of the high cost of preparation. Therefore, future research should consider low-cost preparation methods of nZVI/BC.

\section{Author contribution section}

Conceived and designed the experiments: Qunqun Liu, Yanqing, Sheng, and Wenjing Wang. Performed the experiments: Qunqun Liu, Changyu Li, and Guoqiang Zhao. Analyzed the data: Qunqun Liu. Contributed reagents/materials/analysis tools: Yanqing Sheng and Wenjing Wang. All authors agree with the contribution and declare that they have no actual or potential competing financial interests.

\section{Declaration of competing interest}

The authors declare that they have no known competing financial interests or personal relationships that could have appeared to influence the work reported in this paper.

\section{Acknowledgements}

This study was supported by the Strategic Priority Research Program of the Chinese Academy of Sciences (CAS) (Grant No. XDA23050203), and the National Natural Science Foundation of China (Grant No. 41373100). Additional support was provided by the Regional Key Project of STS of CAS (Grant No. KFJ-STS-QYZX-057), and the Key Research and Development Program of Shandong Province (Grant No. 2019GSF109002).

\section{Appendix A. Supplementary data}

Supplementary data to this article can be found online at https://doi. org/10.1016/j.scitotenv.2020.136650.

\section{References}

Baer, D.R., Gaspar, D.J., Nachimuthu, P., Techane, S.D., Castner, D.G., 2010. Application of surface chemical analysis tools for characterization of nanoparticles. Anal. Bioanal. Chem. 396, 983-1002

Bailey, V.L., Fansler, S.J., Smith, J.L., Bolton, H., 2011. Reconciling apparent variability in effects of biochar amendment on soil enzyme activities by assay optimization. Soil Biol. Biochem. 43, 296-301.

Beiyuan, J., Tsang, D.C.W., Valix, M., Zhang, W., Yang, X., Ok, Y.S., Li, X.D., 2017. Selective dissolution followed by EDDS washing of an e-waste contaminated soil: extraction efficiency, fate of residual metals, and impact on soil quality. Chemosphere 166, 489-496.

Borisover, M., Laor, Y., Parparov, A., Bukhanovsky, N., Lado, M., 2009. Spatial and seasonal patterns of fluorescent organic matter in Lake Kinneret (sea of Galilee) and its catchment basin. Water Res. 43, 3104-3116.

Brym, A., Paerl, H.W., Montgomery, M.T., Handsel, L.T., Ziervogel, K., Osburn, C.L., 2014. Optical and chemical characterization of base-extracted particulate organic matter in coastal marine environments. Mar. Chem. 162, 96-113.

Cai, C., Zhao, M., Yu, Z., Rong, H., Zhang, C., 2019. Utilization of nanomaterials for in-situ remediation of heavy metal (loid) contaminated sediments: a review. Sci. Total Environ. 662, 205-217.

Casida Jr., L., Klein, D., Santoro, T., 1964. Soil dehydrogenase activity. Soil Sci. 98, 371-376. 
Chao, A., Lee, S.M., 1992. Estimating the number of classes via sample coverage. J. Am. Stat. Assoc. 87, 210-217.

Cui, L., Noerpel, M.R., Scheckel, K.G., Ippolito, J.A., 2019. Wheat straw biochar reduces environmental cadmium bioavailability. Environ. Int. 126, 69-75.

Gil-Díaz, M., Pinilla, P., Alonso, J., Lobo, M.C., 2017. Viability of a nanoremediation process in single or multi-metal (loid) contaminated soils. J. Hazard. Mater. 321, 812-819.

Guo, Q., Li, N., Xie, S., 2019. Heavy metal spill influences bacterial communities in freshwater sediments. Arch. Microbiol. 1-8.

Ha, L.T.V., Vanlerberghe, L., Toan, H.T., Dewettinck, K., Messens, K., 2015. Comparative evaluation of six extraction methods for DNA quantification and PCR detection in cocoa and cocoa-derived products. Food Biotechnol. 29, 1-19.

Hu, B., Liang, D., Liu, J., Lei, L., Yu, D., 2014. Transformation of heavy metal fractions on soil urease and nitrate reductase activities in copper and selenium co-contaminated soil. Ecotoxicol. Environ. Saf. 110, 41-48.

Huang, D., Xue, W., Zeng, G. Wan, J., Chen, G., Huang, C., Zhang, C., Cheng, M., Xu, P., 2016. Immobilization of $\mathrm{Cd}$ in river sediments by sodium alginate modified nanoscale zerovalent iron: impact on enzyme activities and microbial community diversity. Water Res. 106, 15-25.

Huang, D., Liu, L., Zeng, G., Xu, P., Huang, C., Deng, L., Wang, R., Wan, J., 2017. The effects of rice straw biochar on indigenous microbial community and enzymes activity in heavy metal-contaminated sediment. Chemosphere 174, 545-553.

Huang, D., Hu, Z., Peng, Z., Zeng, G., Chen, G., Zhang, C., Cheng, M., Wan, J., Wang, X., Qin, X., 2018a. Cadmium immobilization in river sediment using stabilized nanoscale zero-valent iron with enhanced transport by polysaccharide coating. J. Environ. Manag. 210, 191-200.

Huang, D., Qin, X., Peng, Z., Liu, Y., Gong, X., Zeng, G., Huang, C., Cheng, M., Xue, W., Wang, X., Hu, Z., 2018b. Nanoscale zero-valent iron assisted phytoremediation of Pb in sediment: impacts on metal accumulation and antioxidative system of Lolium perenne. Ecotox. Environ. Safe. 153, 229-237.

Huguet, A., Vacher, L., Relexans, S., Saubusse, S., Froidefond, J.M., Parlanti, E., 2009. Properties of fluorescent dissolved organic matter in the Gironde estuary. Org. Geochem. 40, 706-719.

Inyang, M.I., Gao, B., Yao, Y., Xue, Y., Zimmerman, A., Mosa, A., Pullammanappallil, P., Ok, Y.S., Cao, X., 2016. A review of biochar as a low-cost adsorbent for aqueous heavy metal removal. Crit. Rev. Environ. Sci. Technol. 46, 406-433.

Kasemodel, M.C., Sakamoto, I.K., Varesche, M.B.A., Rodrigues, V.G.S., 2019. Potentially toxic metal contamination and microbial community analysis in an abandoned $\mathrm{Pb}$ and Zn mining waste deposit. Sci. Total Environ. 675, 367-379.

Li, X., Yang, Z., Zhang, C., Wei, J., Zhang, H., Li, Z., Ma, C., Wang, M., Chen, J., Hu, J., 2019. Effects of different crystalline iron oxides on immobilization and bioavailability of Cd in contaminated sediment. Chem. Eng. J. 373, 307-317.

Lin, B., Hyacinthe, C., Bonneville, S., Braster, M., Van Cappellen, P., Röling, W.F., 2007. Phylogenetic and physiological diversity of dissimilatory ferric iron reducers in sediments of the polluted Scheldt estuary, Northwest Europe. Environ. Microbiol. 9, 1956-1968.

Liu, S.J., Liu, Y.G., Tan, X.F., Zeng, G.M., Zhou, Y.H., Liu, S.B., Yin, Z.H., Jiang, L.H., Li, M.F., Wen, J., 2018. The effect of several activated biochars on Cd immobilization and microbial community composition during in-situ remediation of heavy metal contaminated sediment. Chemosphere 208, 655-664.

Liu, Q., Wang, F., Meng, F., Jiang, L., Li, G., Zhou, R., 2018. Assessment of metal contamination in estuarine surface sediments from Dongying City, China: use of a modified ecological risk index. Mar. Pollut. Bull. 126, 293-303.

Lovley, D.R., 1991. Dissimilatory Fe (III) and Mn (IV) reduction. Microbiol. Rev. 55, 259-287.

Luo, L., Ma, C., Ma, Y., Zhang, S., Lv, J., Cui, M., 2011. New insights into the sorption mechanism of cadmium on red mud. Environ. Pollut. 159, 1108-1113.

Luo, H., Lin, Q., Zhang, X., Huang, Z., Liu, S., Jiang, J., Xiao, R., Liao, X., 2019. New insights into the formation and transformation of active species in $\mathrm{nZVI} / \mathrm{BC}$ activated persulfate in alkaline solutions. Chem. Eng. J. 359, 1215-1223.

Mackie, K.A., Marhan, S., Ditterich, F., Schmidt, H.P., Kandeler, E., 2015. The effects of biochar and compost amendments on copper immobilization and soil microorganisms in a temperate vineyard. Agric. Ecosyst. Environ. 201, 58-69.

Mahar, A., Wang, P., Li, R., Zhang, Z., 2015. Immobilization of lead and cadmium in contaminated soil using amendments: a review. Pedosphere 25, 555-568.

Moreno, J.L., Garcia, C., Hernandez, T., 2003. Toxic effect of cadmium and nickel on soil enzymes and the influence of adding sewage sludge. Eur. J. Soil Sci. 54, 377-386.

$\mathrm{Mu}$, Y., Jia, F., Ai, Z., Zhang, L., 2017. Iron oxide shell mediated environmental remediation properties of nano zero-valent iron. Environ. Sci-Nano 4, 27-45.

Muehe, E.M., Obst, M., Hitchcock, A., Tyliszczak, T., Behrens, S., Schröder, C., Byrne, J.M., Michel, F.M., Krämer, U., Kappler, A., 2013. Fate of Cd during microbial Fe (III) mineral reduction by a novel and Cd-tolerant Geobacter species. Environ. Sci. Technol. 47, 14099-14109.

Nielsen, U.N., Ayres, E., Wall, D.H., Bardgett, R.D., 2011. Soil biodiversity and carbon cycling: a review and synthesis of studies examining diversity-function relationships. Eur. J. Soil Sci. 62, 105-116.

Oyetibo, G.O., Miyauchi, K., Huang, Y., Ikeda-Ohtsubo, W., Chien, M.F., Ilori, M.O., Amund, O.O., Endo, G., 2019. Comparative geochemical evaluation of toxic metals pollution and bacterial communities of industrial effluent tributary and a receiving estuary in Nigeria. Chemosphere 227, 638-646.

Peng, Q.A., Shaaban, M., Wu, Y., Hu, R., Wang, B., Wang, J., 2016. The diversity of iron reducing bacteria communities in subtropical paddy soils of China. Appl. Soil Ecol. 101, 20-27.
Qin, X., Huang, Q., Liu, Y., Zhao, L., Xu, Y., Liu, Y., 2019. Effects of sepiolite and biochar on microbial diversity in acid red soil from southern China. Chem. Ecol. 1-15.

Rickard, A.H., McBain, A.J., Stead, A.T., Gilbert, P., 2004. Effects of fluid shear force upon the diversity and species interactions within freshwater biofilms. Appl. Environ. Microbiol. 70, 7426-7435.

SSC (Soil Society of China), 2000. Conventional Analytical Method of Soil Agrochemistry. China Agricultural Science and Technology Press.

Sun, Y., Sun, G., Xu, Y., Wang, L., Lin, D., Liang, X., Shi, X., 2012. In situ stabilization remediation of cadmium contaminated soils of wastewater irrigation region using sepiolite. J. Environ. Sci. 24, 1799-1805

Sun, Y., Sun, G., Xu, Y., Liu, W., Liang, X., Wang, L., 2016. Evaluation of the effectiveness of sepiolite, bentonite, and phosphate amendments on the stabilization remediation of cadmium-contaminated soils. J. Environ. Manag. 166, 204-210.

Sun, Y., Iris, K.M., Tsang, D.C., Cao, X., Lin, D., Wang, L., Graham, N.j., Alessi, D.S., Komárek M., Ok, Y.S., Feng, Y., Li, X., 2019. Multifunctional iron-biochar composites for the removal of potentially toxic elements, inherent cations, and hetero-chloride from hydraulic fracturing wastewater. Environ. Int. 124, 521-532.

Taneez, M., Hurel, C., 2019. A review on the potential uses of red mud as amendment for pollution control in environmental media. Environ. Sci. Pollut. Res. 1-20.

Wang, X., Hu, M., Xia, Y., Wen, X., Ding, K., 2012. Pyrosequencing analysis of bacterial diversity in 14 wastewater treatment systems in China. Appl. Environ. Microbiol. 78 7042-7047.

Wang, L., Tsang, D.C.W., Poon, C.S., 2015. Green remediation and recycling of contaminated sediment by waste-incorporated stabilization/solidification. Chemosphere $122,257-264$.

Wang, Y., Zhang, X., Zhang, X., Meng, Q., Gao, F., Zhang, Y., 2017. Characterization of spectral responses of dissolved organic matter (DOM) for atrazine binding during the sorption process onto black soil. Chemosphere 180, 531-539.

Wan, J., Zeng, G., Huang, D., Hu, L., Xu, P., Huang, C., Deng, R., Xue, W., Lai, C., Zhou, C. Zheng, K., Ren, X., Gong, X., 2018. Rhamnolipid stabilized nano-chlorapatite: synthesis and enhancement effect on Pb-and Cd-immobilization in polluted sediment J. Hazard. Mater. 343, 332-339.

Wang, L., Chen, S.S., Sun, Y., Tsang, D.C., Yip, A.C., Ding, S., Hou, D., Baek, K., Ok, Y.S., 2019 Efficacy and limitations of low-cost adsorbents for in-situ stabilisation of contaminated marine sediment. J. Clean. Prod. 212, 420-427.

Xu, M. Xia, H., Wu, J., Yang G, Zhang X., Peng, H., Yu, X, Li, L, Xiao, H, Oi, H. 2017. Shifts in the relative abundance of bacteria after wine-lees-derived biochar intervention in multi metal-contaminated paddy soil. Sci. Total Environ. 599, 1297-1307.

Xu, H., Zou, L., Guan, D., Li, W., Jiang, H., 2019. Molecular weight-dependent spectral and metal binding properties of sediment dissolved organic matter from different origins. Sci. Total Environ. 665, 828-835.

Xu, H., Cai, H., Yu, G., Jiang, H., 2013. Insights into extracellular polymeric substances of cyanobacterium Microcystis aeruginosa using fractionation procedure and parallel factor analysis. Water Res. 47, 2005-2014.

Xu, Y., Qi, F., Bai, T., Yan, Y., Wu, C., An, Z., Luo, S., Huang, Z., Xie, P., 2019. A further inquiry into co-pyrolysis of straws with manures for heavy metal immobilization in manurederived biochars. J. Hazard. Mater. 380, 120870.

Xue, W., Huang, D., Zeng, G., Wan, J., Zhang, C., Xu, R., Cheng, M., Deng, R., 2018a. Nanoscale zero-valent iron coated with rhamnolipid as an effective stabilizer for immobilization of $\mathrm{Cd}$ and $\mathrm{Pb}$ in river sediments. J. Hazard. Mater. 341, 381-389.

Xue, W., Peng, Z., Huang, D., Zeng, G., Wan, J., Xu, R., Cheng, R., Zhang, C., Jiang, D., Hu, Z., 2018b. Nanoremediation of cadmium contaminated river sediments: microbial response and organic carbon changes. J. Hazard. Mater. 359, 290-299.

Yamashita, Y., Jaffé, R., Maie, N., Tanoue, E., 2008. Assessing the dynamics of dissolved organic matter (DOM) in coastal environments by excitation emission matrix fluorescence and parallel factor analysis (EEM-PARAFAC). Limnol. Oceanogr. 53, 1900-1908.

Yang Z.H. Xu, R. Zheng Y, Chen, T, Zhao, LJ., Li, M., 2016. Characterization of extracellular polymeric substances and microbial diversity in anaerobic co-digestion reactor treated sewage sludge with fat, oil, grease. Bioresour. Technol. 212, 164-173.

Yang, F., Zhang, S., Sun, Y., Cheng, K., Li, J., Tsang, D.C., 2018. Fabrication and characterization of hydrophilic corn stalk biochar-supported nanoscale zero-valent iron composites for efficient metal removal. Bioresour. Technol. 265, 490-497.

Yang, X., Tsibart, A., Nam, H., Hur, J., El-Naggar, A., Tack, F.M., Wang, C., Lee, Y., Tsang, D. Ok, Y.S., 2019. Effect of gasification biochar application on soil quality: trace metal behavior, microbial community, and soil dissolved organic matter. J. Hazard. Mater. 365, 684-694.

Yin, H., Zhu, J., 2016. In situ remediation of metal contaminated lake sediment using naturally occurring, calcium-rich clay mineral-based low-cost amendment. Chem. Eng. J. 285, 112-120

Zhang, C., Ge, Y., Yao, H., Chen, X., Hu, M., 2012. Iron oxidation-reduction and its impacts on cadmium bioavailability in paddy soils: a review. Front. Env. Sci. Eng. 6, 509-517.

Zhang, Y., Li, Y., Dai, C., Zhou, X., Zhang, W., 2014. Sequestration of Cd (II) with nanoscale zero-valent iron (nZVI): characterization and test in a two-stage system. Chem. Eng. J. 244, 218-226.

Zhao, X., Huang, J., Lu, J., Sun, Y., 2019. Study on the influence of soil microbial community on the long-term heavy metal pollution of different land use types and depth layers in mine. Ecotox. Environ. Safe. 170, 218-226. 